\title{
Changes in the prevalence of measures associated with hypertension among Iranian adults according to classification by ACC/AHA guideline 2017
}

\author{
Mohsen Mirzaei ${ }^{1} \mathbb{D}$, Masoud Mirzaei ${ }^{1} \mathbb{B}$, Mojtaba Mirzaei ${ }^{2}$ (D) and Behnam Bagheri ${ }^{3^{*}}$ (D)
}

\begin{abstract}
Background: Different definitions have been proposed to categorize hypertension. We aimed to investigate the difference in prevalence of measures associated with hypertension according to the American College of Cardiology/American Heart Association (ACC/AHA) criteria versus Joint National Committee 7 (JNC7) criteria.

Methods: We analyzed the data of 10,000 participants of Yazd Health Study (YaHS) aged 20-69 years. Blood pressure was measured three times with standard protocol defined by ACC/AHA. Prevalence of high blood pressure measure was compared in both definitions and absolute differences reported.

Results: The prevalence of high blood pressure in our measurement was 61.0\% according to ACC/AHA, and 28.9\% according to JNC 7. The prevalence of self-reported hypertension was $18.6 \%$. Age and sex standardized prevalence rates of high blood pressure measure indicates a 2.4 -fold increase in the prevalence rate ( $30.1 \%$ absolute difference) by the ACC/AHA guideline. While the prevalence increased in all age groups, the age group of 20-29 showed the highest relative increase by 3.6 times (10.6\% vs. $38.1 \%)$. High blood pressure measure among people with diabetes increased from 45.8 to $75.3 \%$ with the ACC/AHA guideline. Of the people who had no past history of diagnosed hypertension ( $n=7887), 55.1$ and $22.7 \%$ had high blood pressure measure by ACC/AHA and JNC-7 guidelines, respectively. From JNC7 to ACC/AHA, the overall difference in unawareness about HTN increased by $32.4 \%$.

Conclusion: Prevalence of hypertension associated measures increased over two folds by using the ACC/AHA criteria compared to JNC 7. Also, change in the criteria, reduces awareness of the disease and increases uncontrolled hypertension respectively. More research is needed to determine if the new definitions can affect management of hypertension in societies. Considering local priorities and implication of cost effective may improve implementation of new definitions for hypertension in different countries.
\end{abstract}

Keywords: Hypertension, Prevalence, 2017 ACC/AHA hypertension guideline

*Correspondence: behnambagheri222@gmail.com

${ }^{3}$ Shahediah Cohort Study, Shahid Sadoughi University of Medical Sciences, Yazd, Iran

Full list of author information is available at the end of the article

C The Author(s). 2020 Open Access This article is licensed under a Creative Commons Attribution 4.0 International License, which permits use, sharing, adaptation, distribution and reproduction in any medium or format, as long as you give appropriate credit to the original author(s) and the source, provide a link to the Creative Commons licence, and indicate if changes were made. The images or other third party material in this article are included in the article's Creative Commons licence, unless indicated otherwise in a credit line to the material. If material is not included in the article's Creative Commons licence and your intended use is not permitted by statutory regulation or exceeds the permitted use, you will need to obtain permission directly from the copyright holder. To view a copy of this licence, visit http://creativecommons.org/licenses/by/4.0/. The Creative Commons Public Domain Dedication waiver (http://creativecommons.org/publicdomain/zero/1.0/) applies to the data made available in this article, unless otherwise stated in a credit line to the data. 


\section{Background}

Hypertension (HTN) is a global public health crisis; it is the most important risk factor for people with cardiovascular disease, which is one of the main causes of death and life lost in the world [1]. The prevalence of HTN was reported $20-50 \%$ across different world regions due to its differences in environmental and genetic factors and also changes in the study protocol [2]. In Asia, the prevalence was estimated 15-35\%, in the Eastern Mediterranean Region (EMR) 29\% and in Iran 18-23\% [3-5]. In 2017, High blood pressure was the second most common risk factor for men and the first common risk factor for women [6]. In the past decades, due to the rapid socio-economic and lifestyle changes, the prevalence of non-communicable diseases such as hypertension has been increased in developing countries more than developed countries (7.7\% compared to 2.6\%) [7]. Blood pressure over $120 / 80 \mathrm{mmHg}$ is linearly associated with the risk of cardiovascular disease, with an increase of 20 $\mathrm{mmHg}$ in systolic blood pressure and $10 \mathrm{mmHg}$ in diastolic blood pressure, increase doubled the risk [8].

In 2017, the American College of Cardiology/American Heart Association (2017 ACC/AHA) guideline introduced a new classification for high blood pressure in adults which was a change in the clinical hypertension guide since 2003. In the ACC/AHA definition, with a decrease of $10 \mathrm{mmHg}$, the systolic blood pressure $\geq 130$ and diastolic $\geq 80 \mathrm{mmHg}$ are considered hypertension. In this guide, instead of the "pre-hypertension" category, a new group named "elevated hypertension" has been introduced [9]. According to this ACC/AHA guideline, people who have previously been classified as prehypertensive will be considered hypertensive. This new definition aimed at persuading patients to change lifestyles and use medications to reduce blood pressure. Early intervention for the care and control of hypertension reduces mortality and morbidity of cardiovascular disease [9].

Due to the difference in the prevalence of the disease in different regions, this new approach has prompted researchers to update their findings from surveillances of hypertension. Muntner and colleagues show that the prevalence of hypertension among Americans over 20 years of age increases by $14.7 \%$, according to the ACC/AHA definition [10]. Another study shows a relative increase in the prevalence of 45.1 and $26.8 \%$ of the disease among 45-75 years-old in the United States and China [11]. Therefore, a significant number of adults over the age of 20 in the United States are unaware of their hypertension, are not being treated, or are not controlled their blood pressure adequately. The number of these people are more than 50 million people or 1 in 4 people of all men and 1 in 5 of all women [12]. The study of
Khera in Nepal shows a $23 \%$ increase in the prevalence of high blood pressure with the ACC/AHA definition [13]. In Bangladesh, the difference was reported as $22.3 \%$ [14].

The purpose of this study was to estimate the prevalence of hypertension associated measures in a large number of adults in an Iranian population according to the new guidelines (ACC/AHA 2017) and compare it with the old definition (JNC 7). The difference between the two guidelines in the prevalence of hypertension associated measures is a guide for health managers to revise intervention programs for disease control accordingly.

\section{Methods}

Yazd Health Study (YaHS) is a prospective cohort study conducted since 2014 to determine determinants of non-communicable disease and related risk factors in Yazd Greater Area which is located in the center of Iran. Details of YaHS have been published elsewhere [15]. Briefly, 10,000 residents of Yazd Greater Area at the age of 20 to 69 years were selected using cluster random sampling method. Fifty people interviewed in each cluster with 50 people ( 25 males and 25 females), in which five individuals were selected from each age group.

A valid questionnaire was completed at home visits. In follow-up, the final overall response rate was $98 \%$. The previous history of HTN diagnosis by a physician was documented according to self-report. Self-reported hypertension has been recorded with a positive answer to the question, "have you ever been told by your physician that you have high blood pressure?" An English version of the YaHS questionnaire has been published elsewhere [16]. Also, it can be accessed at the study website from the address: http://www.yahs-ziba.com. At the physical examination, three blood pressures (BP) were measured by trained and certified person at home visit (out-of-office method) using standard method with appropriate cuff sizes for participants' arm [17]. Blood pressure was measured in a sitting position after twothirds of the interview questions were completed, so the interviewees had been in rest for at least $40 \mathrm{~min}$ at the time of measurement. It was ensured that sphygmomanometer cuff, used to measure BP, was at the level of the heart and the cuff was deflated slowly. Blood pressure measurements were repeated three times with $5 \mathrm{~min}$ interval using electronic sphygmomanometers (Model N-Champion, Reichter GMBH, Germany) which were calibrated regularly. The mean of the second and third measurements was recorded as blood pressure, which was used for analysis [14, 15, 18, 19].

Measured BP was classified into normal, prehypertension, hypertension stage-1, and hypertension stage-2 by Joint National Committee (JNC 7) classification for adults [18]. The 2017 ACC/AHA guideline has 
Table 1 Blood Pressure classifications by JNC 7 and 2017 ACC/AHA guideline

\begin{tabular}{|c|c|c|c|c|}
\hline Systolic BP (mm Hg) & & Diastolic BP (mm Hg) & $\mathrm{JNC} 7^{\mathrm{a}}$ & 2017 ACC/AHA ${ }^{\mathrm{b}}$ \\
\hline$<120$ & And & $<80$ & Normal & Normal \\
\hline $120-129$ & And & $<80$ & Pre-hypertension & Elevated BP \\
\hline 130-139 & Or & $80-89$ & Pre-hypertension & hypertension-Stage 1 \\
\hline $140-159$ & Or & $90-99$ & hypertension-Stage 1 & hypertension-Stage 2 \\
\hline$\geq 160$ & or & $\geq 100$ & hypertension-Stage 2 & hypertension-Stage 2 \\
\hline
\end{tabular}

${ }^{\mathrm{a}}$ Seventh Report of the Joint National Committee

b 2017 American College of Cardiology (ACC)/ American Heart Association (AHA) guideline

changed the definition of high blood pressure and its classification; the definition of hypertension was systolic $\mathrm{BP} \geq 130 \mathrm{mmHg}$ and/or a diastolic $\mathrm{BP}$ of $\geq 80 \mathrm{mmHg}$. In other words, the cut-off point reduced by $10 \mathrm{mmHg}$ for systolic BP and $5 \mathrm{mmHg}$ for diastolic BP. Additionally, the definition of pre-hypertension has been changed and a new class called elevated blood pressure has been introduced. Therefore, the definition of stage- 1 and stage2 hypertension has undergone a change. The Table 1 shows the comparison of hypertension classification by JNC 7 and ACC/AHA [19].

Body Mass Index (BMI) calculated as weight $/$ height $^{2}$ in $\mathrm{kg} / \mathrm{m}^{2}$ and was categorized to; underweight, normal, overweight, and obese according to the World Health Organization (WHO) cut-off point's recommendation [20].

Mean BP level values \pm standard deviations (SD) were calculated by demographic data and past medical history. The prevalence of hypertension associated measures was described as proportions with $95 \%$ confidence intervals (CI). Age-standardized prevalence rates were calculated using the direct method according to 2016 Yazd population census. The absolute differences in prevalence of high blood pressure measures according to guidelines were calculated separately. A chi-square test was used to detect the significance of change. All statistical analyses were performed using SPSS version 16 software. A $p$-value less than 0.05 were considered statistically significant.

The research proposal was approved by the ethics committee of Shahid Sadoughi University of Medical Science, Yazd, Iran No: IR.SSU.MEDICINE.REC.1396.311. The study was explained to all respondents willing to participate. All participants had the right to withdraw from the study at any time. Informed consent was obtained from each participant before data collection. Participants with new diagnostics of hypertension were advised to refer their health center or physician for the follow-up.

\section{Results}

In this study, the blood pressure of 9861 adults was measured three times. Of total, $18.6 \%$ had self-reported hypertension. The crude prevalence of high blood pressure associated with HTN according to JNC 7 guideline was $28.9 \%$ (CI 95\%: 27.9-29.7), and according to the ACC/AHA 2017 was 61.0\% (95\% CI: 60.1-62.0\%); an absolute increase of $32.1 \%$. Age and sex standardized prevalence rates of high blood pressure was 21.6 and 51.7\% according to JNC7 guideline and ACC/AHA 2017, respectively. This indicated a 2.4 -fold increase in the prevalence rate accordingly ( $30.1 \%$ absolute difference). Of the people who had no past history of hypertension ( $n=7887), 22.7$ and $55.1 \%$ had high blood pressure by JNC-7 and ACC/AHA 2017 guidelines, respectively who were not aware of their illness and were not being treated.

Two-thirds of men have blood pressure measure in the range of HTN according to ACC/AHA guideline (compared to $32.5 \%$ according to the previous classification). This increased absolute prevalence is higher in men compared with women $(35.0 \%$ vs. $29.5 \%)$. With aging, the prevalence of hypertension associated measures increased, but the highest absolute increase was seen in the group 40-49 years old with the ACC/AHA definitions (35\%). In the age of $20-29$ years, the prevalence of high blood pressure measurement increased approximately 4 times $(10.6 \%$ vs. $38.1 \%)$.With the ACC/ AHA definition, about $69 \%$ of obese people have high blood pressure by ACC/AHA 2017 guideline, compared with $38.6 \%$ by JNC 7 . With the new guideline, three out of four diabetic patients were in the hypertensive group, which shows an absolute increase of 30\% (Table 2).

Table 2 shows the characteristics of the participants and comparison of hypertension associated measures according to both guidelines (JNC-7 \& ACC/AHA 2017) in different groups. With the ACC/AHA 2017 was observed a crude increase of $24 \%$ or more in the prevalence of hypertension associated measures in all age-sex groups, education and people with a history of diabetes. This change is also seen in people who are overweight or obese; even with a normal body mass index. The highest increased proportion is seen in men $40-49$ year's age groups.

Mean systolic and diastolic BP in the population were $126.5 \pm 18.4 \mathrm{mmHg}$ and $80.2 \pm 12.5 \mathrm{mmHg}$, respectively. 
Table 2 Characteristics of the Yazd Health Study participants (20-69 years) and the prevalence of hypertension associated measures by both guidelines in 2014-15

\begin{tabular}{|c|c|c|c|c|}
\hline \multirow[t]{2}{*}{ Variables } & \multirow{2}{*}{$\begin{array}{l}\text { Total } \\
\text { Num. (\%) }\end{array}$} & \multicolumn{2}{|c|}{ Prevalence of hypertension associated measures } & \multirow{2}{*}{$\begin{array}{l}\text { Difference } \\
\%\end{array}$} \\
\hline & & $\begin{array}{l}\text { JNC-7 } \\
\text { Num. (\%, Cl 95\%) }\end{array}$ & $\begin{array}{l}\text { ACC/AHA2017 } \\
\text { Num. (\%, Cl 95\%) }\end{array}$ & \\
\hline \multicolumn{5}{|l|}{ Sex } \\
\hline Male & $4883(49.5)$ & $1585(32.5,31.2-32.5)$ & $3152(66.5,63.2-65.9)$ & +34.0 \\
\hline Female & $4978(50.5)$ & $1275(25.6,24.4-26.8)$ & $2617(53.8,52.4-55.2)$ & +28.2 \\
\hline \multicolumn{5}{|l|}{ Age groups } \\
\hline $20-29$ & $1952(19.8)$ & $206(10.6,9.3-12.0)$ & $737(38.1,36.0-40.3)$ & +27.5 \\
\hline $30-39$ & $2015(20.5)$ & $355(17.6,16.0-19.3)$ & $1026(51.4,49.2-53.6)$ & +33.8 \\
\hline $40-49$ & $2042(20.7)$ & $592(28.9,27.1-31.0)$ & $1273(64.0,61.9-66.1)$ & +35.1 \\
\hline $50-59$ & $1957(19.8)$ & $724(37.0,34.9-39.2)$ & $1338(70.3,68.2-72.3)$ & +33.3 \\
\hline $60-69$ & $1893(19.2)$ & $965(50.9,48.7-53.2)$ & $1394(78.0,76.0-79.9)$ & +27.1 \\
\hline \multicolumn{5}{|l|}{ Education } \\
\hline Primary school and less & $2550(26.1)$ & $1089(42.7,40.8-44.6)$ & $1784(73.1,71.3-74.7)$ & +29.4 \\
\hline High school & $2783(28.5)$ & $808(29.0,27.4-30.7)$ & $1688(62.1,60.2-63.9)$ & +33.1 \\
\hline Diploma and Graduate Diploma & $2899(29.7)$ & $624(21.5,20.1-23.0)$ & $1521(53.4,51.5-55.2)$ & +31.9 \\
\hline BSc,MSc. and Doctorate & $1535(15.7)$ & $296(19.3,17.4-21.3)$ & $725(48.0,45.5-50.5)$ & +28.7 \\
\hline \multicolumn{5}{|l|}{ BMI (kg/m2) } \\
\hline Underweight $(<18.5)$ & $299(3.0)$ & $27(9.0,6.3-12.8)$ & $80(26.9,22.2-32.3)$ & +17.9 \\
\hline Normal (18.5-24.5) & $3149(32.0)$ & $614(19.5,18.1-20.9)$ & $1520(49.2,47.5-51.0)$ & +29.7 \\
\hline Overweight (25.0-29.9) & 3796 (38.6) & $1193(31.4,29.9-32.9)$ & $2368(64.1,62.5-65.6)$ & +32.7 \\
\hline Obesity $(\geq 30.00)$ & $2601(26.4)$ & $1003(38.6,36.7-40.4)$ & $1795(71.4,69.6-73.1)$ & +32.8 \\
\hline \multicolumn{5}{|l|}{ History of hypertension } \\
\hline Yes & $1800(18.6)$ & $1069(59.4,57.1-61.4)$ & $1402(83.6,81.7-85.3)$ & +24.2 \\
\hline No & $7887(81.4)$ & $1743(22.1,21.2-23.0)$ & $4275(55.1,54.0-56.2)$ & +33.0 \\
\hline \multicolumn{5}{|l|}{ History of diabetes mellitus? mellitus } \\
\hline Yes & $1386(14.1)$ & $635(45.8,43.2-48.4)$ & $999(75.3,72.9-77.6)$ & +29.5 \\
\hline No & $8420(85.9)$ & $2194(26.1,25.1-27.0)$ & $4732(57.5,56.4-58.6)$ & +31.4 \\
\hline
\end{tabular}

Men had higher mean systolic and diastolic BP than women in the study participants. The mean systolic and diastolic BP increases with age, less education and higher body mass index. This trend is similar in both sexes. According to the ACC/AHA classification, $19.1 \%$ of the individuals with systolic HTN (130-139 mmHg) which corresponds to pre-hypertension in the previous definition were associated with hypertension-stage 1 . For diastolic blood pressure, this difference was $33.7 \%$.

Table 3 shows that the new classification of $61 \%$ of the adults according to systolic blood pressure and $48 \%$ according to diastolic blood pressure changed with the new definitions. This change can potentially initiate preventive and therapeutic interventions for these individuals as compared to the previous definition.

The 2017 ACC/AHA guideline was associated with an increase in most of the HTN categories in our study. Men had a higher absolute increase in prevalence than women. A similar increase was observed for hypertension stage 1 and 2 for both sexes. But the increase in hypertension-stage 2 was higher in men than in women $(22.1 \%$ vs. $17.1 \%)$. Table 4 shows the difference in the stages of the two definitions of hypertension by sex. This increase in the percentage of hypertensionstage 2 was also seen in different age groups. As shown in Fig. 1, this difference is more pronounced in younger adults and may cause interventions to begin at a lower age.

\section{Discussion}

About $60 \%$ of the study populations had blood pressure associated with HTN according to AHA/ACC guideline, about twice the prevalence by JNC-7 threshold, however the ratio of men to women with hypertension remains almost the same according to either guideline (1.3 vs. 1.2). More than half of the participants with hypertension who did not have any history of diagnosed hypertension will have high blood pressure according to the 
Table 3 Frequency distribution of blood pressure levels in adult residents of Yazd Greater Area aged 20-69 years in 2014-2015

\begin{tabular}{|c|c|c|c|}
\hline Blood Pressure level $(\mathrm{mm} \mathrm{Hg})$ & $\begin{array}{l}\text { Male } \\
\text { Num. (\%, Cl 95\%) }\end{array}$ & $\begin{array}{l}\text { Female } \\
\text { Num. (\%, Cl 95\%) }\end{array}$ & $\begin{array}{l}\text { Total } \\
\text { Num. (\%, Cl 95\%) }\end{array}$ \\
\hline \multicolumn{4}{|l|}{ Systolic BP } \\
\hline$<120$ & $1278(26.2,25.0-27.4)$ & $1987(39.9,38.6-41.3)$ & $3265(33.1,32.2-34.0)$ \\
\hline $120-129$ & $1412(28.9,27.7-30.2)$ & $1227(24.6,23.5-25.9)$ & $2639(26.8,25.9-27.6)$ \\
\hline 130-139 & $1071(21.9,20.8-23.1)$ & $816(16.4,15.4-17.4)$ & $1887(19.1,18.4-19.9)$ \\
\hline $140-149$ & $600(12.3,11.4-13.2)$ & $448(9.0,8.2-9.8)$ & $1048(10.6,10.0-11.2)$ \\
\hline $150-159$ & $215(4.4,3.9-5.0)$ & $217(4.4,3.8-5.0)$ & $432(4.4,4.0-4.8)$ \\
\hline \multirow[t]{2}{*}{$\geq 160$} & $307(6.3,5.6-7.0)$ & $283(5.7,5.1-6.4)$ & $590(6.0,5.5-6.5)$ \\
\hline & $P$ value: $<0.0001$ & & \\
\hline \multicolumn{4}{|l|}{ Diastolic BP } \\
\hline$\leq 79$ & $1954(40.0,38.6-41.4)$ & $2638(53.0,51.6-54.4)$ & $4592(46.6,45.6-47.5)$ \\
\hline $80-89$ & $1797(36.8,35.5-38.2)$ & $1523(30.6,29.3-31.2)$ & $3320(33.7,32.7-34.6)$ \\
\hline $90-99$ & $798(16.3,15.3-17.4)$ & $597(12.0,11.1-12.9)$ & $1395(14.1,13.5-14.8)$ \\
\hline \multirow[t]{2}{*}{$\geq 100$} & $334(6.8,6.2-7.6)$ & $221(4.4,3.9-5.1)$ & $555(5.6,5.2-6.1)$ \\
\hline & $P$ value: $<0.0001$ & & \\
\hline
\end{tabular}

ACC/AHA guideline. High blood pressure was more prevalent among males and those with lower education and higher BMI.

In a study by Esteghamati et al. a similar hypertension prevalence of $25.6 \%$ among Iranian adults according to JNC-7 criteria was reported [21]. However, another study of the rural population in Iran showed a prevalence of $41.8 \%$ [22]. as expected, the prevalence of hypertension will increase according to AHA/ACC guideline with low thresholds. The amount of this increase was not the same among different studies in Iran and other countries. While we reported an increase of over two folds, another study in Iran found an increase of about three folds from 12.6 to $42.7 \%$ from the fifth

Table 4 Comparison of hypertension associated measures in males and females residents of Yazd Greater area according to JNC7 and ACC/AHA 2017 guidelines 2014-2015

\begin{tabular}{|c|c|c|c|}
\hline Hypertension Prevalence by BP measurement & $\begin{array}{l}\text { JNC } 7 \\
\text { Num. (\%, Cl 95\%) }\end{array}$ & $\begin{array}{l}\text { ACC/AHA2017 } \\
\text { Num. (\%, CI 95\%) }\end{array}$ & $\begin{array}{l}\text { Difference } \\
\%\end{array}$ \\
\hline \multicolumn{4}{|l|}{ Male (N:4883) } \\
\hline Normal & $978(20.0,18.9-21.2)$ & $978(20.0,18.9-21.2)$ & 0 \\
\hline Pre-hypertension/elevated blood & $2320(47.5,46.1-48.9)$ & $613(12.6,11.6-13.5)$ & -34.9 \\
\hline Stage-1 hypertension & $1075(22.0,20.9-23.2)$ & $1707(35.0,33.6-36.3)$ & +13 \\
\hline Stage-2 hypertension & $510(10.4,9.6-11.3)$ & $1585(32.5,31.2-33.8)$ & +22.1 \\
\hline Hypertension (stage-1 plus stage-2) & $1585(32.4,31.2-33.8)$ & $3292(67.4,66.1-68.7)$ & +35.0 \\
\hline \multicolumn{4}{|l|}{ Female (N:4978) } \\
\hline Normal & $1642(33.0,31.7-34.3)$ & $1642(33.0,31.7-34.3)$ & 0 \\
\hline Pre-hypertension/elevated blood & $2079(41.8,40.4-43.1)$ & $608(12.2,11.3-13.1)$ & -29.6 \\
\hline Stage-1 hypertension & $854(17.2,16.1-18.2)$ & $1471(29.6,28.3-30.8)$ & +12.4 \\
\hline Stage-2 hypertension & $403(8.1,7.4-8.9)$ & $1257(25.2,24.1-26.5)$ & +17.1 \\
\hline Hypertension (stage-1 plus stage-2) & $1257(25.3,24.1-26.5)$ & $2728(54.8,53.4-56.2)$ & +29.5 \\
\hline \multicolumn{4}{|l|}{ Total } \\
\hline Normal & $2620(26.6,25.7-27.4)$ & $2620(26.6,25.7-27.4)$ & 0 \\
\hline Pre-hypertension/elevated blood & $4399(44.6,43.6-45.6)$ & $1221(12.4,11.7-13.0)$ & -32.2 \\
\hline Stage-1 hypertension & $1929(19.6,18.8-20.3)$ & $3178(32.2,31.3-33.2)$ & +12.6 \\
\hline Stage-2 hypertension & $913(9.3,8.7-9.8)$ & $2842(28.8,27.9-29.7)$ & +19.5 \\
\hline Hypertension (stage-1 plus stage-2) & $2842(28.9,27.9-29.7)$ & $6020(61.0,60.1-62.0)$ & +32.1 \\
\hline
\end{tabular}




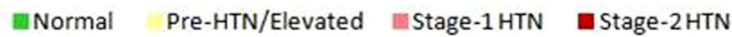

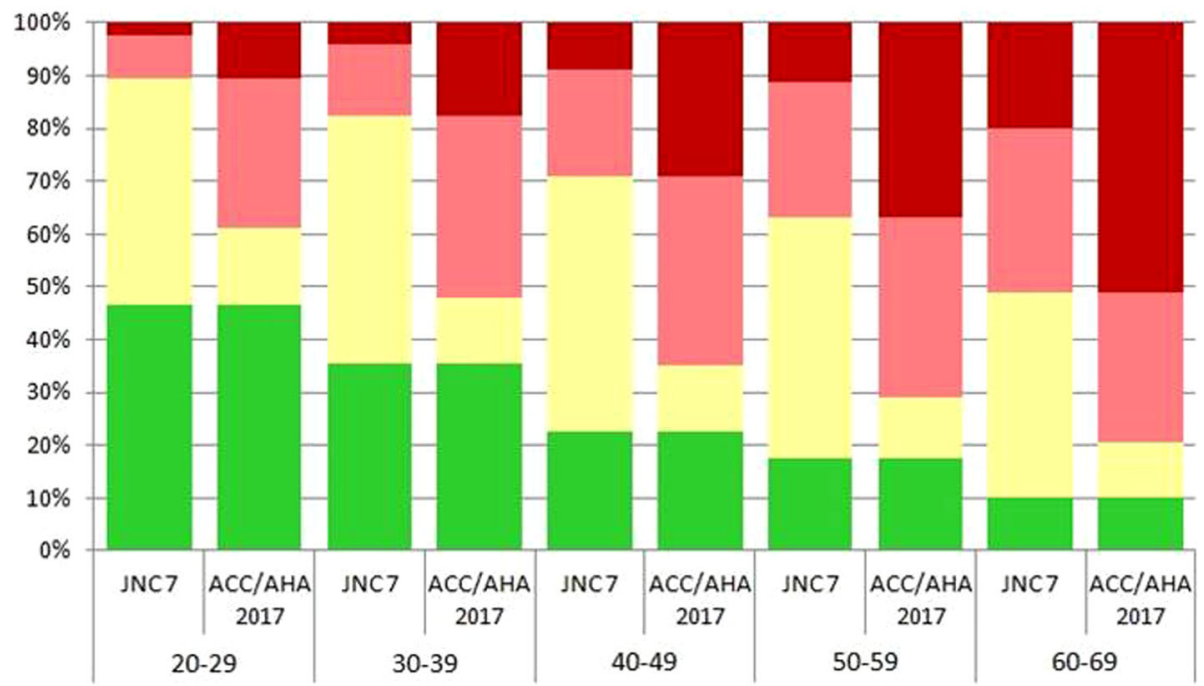

Fig. 1 Prevalence of hypertension associated measures in various age groups by JNC-7 and ACC/AHA 2017 guidelines

phase (2012-2015) of the Tehran Lipid and Glucose Study [23]. An increase of 1.4 times from 31.9 to $45.6 \%$ in United States, [10] 1.6 times from 30.4 to $49.2 \%$ in Korea [24] and 1.9 times in Southwest China [25] was seen in different populations across the world.

According to the AHA/ACC guideline, the prevalence of high blood pressure increased in all age groups but the difference was more prominent in younger age groups in our study. This should not be mixed-up with indication to treatment, as the pharmacologic management of hypertension in the elderly population is the main expected change according to the ACC/AHA guideline. Among those 60-69 years old, 78\% had high blood pressure according to ACC/AHA guidelines in our study; this was $51 \%$ according to JNC-7. The difference between these two figures may indicate the need for mass medications in the population. While JNC-8 guidelines were considered an easier standard for treatment in those older than 60 years compared to JNC-7, [26] the ACC/AHA guideline introduced a stricter target.

The prevalence of high blood pressure among patients with diabetes in our study increased with the ACC/AHA guidelines from 45.8 to $75.3 \%$. However, any benefit from the intervention in a larger population from this new classification remains questionable. The American diabetes association still recommends blood pressure threshold of $140 / 90 \mathrm{mmHg}$ for initiation of pharmacologic therapy which does not agree with the general target of 130/80 for diabetic patients [27]. While one of the main studies behind the AHA/ACC recommendation is the SPRINT trial, those with diabetes were excluded from that study [28]. ACCORD trial in patients with hypertension and diabetes showed no additional benefit of treating blood pressure to $120 \mathrm{mmHg}$ compared to $140 \mathrm{mmHg}$ in those with diabetes [29].

High blood pressure according to the ACC/AHA guideline does not mean an indication for pharmacotherapy. Three months' trial of lifestyle modification is needed for most of those labeled 'hypertensive' according to the new guidelines [9]. Although this difference can change the prevalence of patients labeled with HTN considerably, a study by Muntner et al. [10] showed that the overall impact on indications for treatment will be much less. We were not being able to calculate all the people who need to start pharmacologic therapy according to the ACC/AHA guidelines.

Although the AHA/ACC updated its threshold for HTN, many other American and European associations have not updated their guidelines accordingly. European Society of Cardiology and European Society of Hypertension in their updated guidelines defined hypertension the same as JNC-7 [30]. 'American Academy of Family Physicians' and 'American College of Physicians' still recommend the JNC 7 thresholds and published their guidelines for treatment of hypertension in elderly, accordingly [31]. Multiple thresholds for hypertension and its management have the potential to confuse clinicians and public health policymakers when comparing data from different countries or different time periods.

There is controversy about the negative effects of labeling patients with hypertension. Some studies have reported negative outcomes including distress and higher levels of physical symptoms, increased work absenteeism and lower health-related quality of life, [32-34] while others have shown no negative effect [35]. In addition to this controversy, there is no clear evidence that changing 
HTN threshold will change outcomes. Similar worries arose when introducing the term of "pre-hypertension" in previous guidelines. A study reported no such changes in eating habits, salt intake, alcohol drinking and exercise [36].

In addition to changing hypertension definition, $\mathrm{ACC} /$ AHA guidelines lowered targets for blood pressure management, especially in older population. Pharmacotherapy for lowering blood pressure below $130 / 80 \mathrm{mmHg}$ is now recommended in general population. This may have significant impact, especially in older population. It should be noted that JNC 8 panel members report increased target of blood pressure therapy in those older than 60 years to $150 \mathrm{mmHg}$ which is $20 \mathrm{mmHg}$ higher than current recommendation.

In the past decades, despite an increase in the prevalence of hypertension, control of this condition was improved in the United States [37]. Using the AHA/ACC criteria, temporal comparison of hypertension awareness and management will be more difficult especially in developing countries with limited availability data. In addition to difficulty in temporal comparison, regional comparison will be difficult considering the responsible authority. Even according to the JNC guideline, a considerable proportion of population was unaware of their hypertension status. The proportion will be increased more than twice by application of the new AHA/ACC guideline.

Although there is controversy about the new definition of hypertension among medical authorities around the world, the threshold of normal blood pressure and recommendations for medical treatment is much more similar. Different terms for describing hypertension levels such as "elevated", "pre-hypertension" and "stage 1 hypertension" may cause confusion for providers and patients. The use of similar and equivalent terms can simplify the doctor-patient communication and facilitate the analysis of public health trends over time. Non-medical management of high blood pressure should be tailored to the culture of local communities and not necessarily limited to the specific terms for describing high blood pressure.

\section{Limitation}

This is a cross-sectional study with three consequent BP measurements with 5 min' interval. Although measuring blood pressure in two occasions was recommended to label patients with hypertension, we only measured blood pressure in 1 day for this study due to the large sample size and logistic issues. However, we tried to increase accuracy by repeating the measurement and report the average of the last two times similar to other large epidemiologic studies. Inter-observer differences in measuring blood pressure can lead to misclassification.
However, our interviewers were trained in practical courses and digital calibrated sphygmomanometer was used with minimum interpretation by the interviewers.

\section{Conclusion}

This study shows that the ACC/AHA guideline puts the blood pressure of a significant proportion of adults in the range of hypertension. This public health problem calls for more comprehensive interventions to prevent and control hypertension. Changes in HTN definition may prompt people to change their lifestyles sooner and further investigation into the initiation of medical treatment is warranted. In addition, differences in the prevalence of cardiovascular risk factors, unhealthy lifestyle, and health care systems in countries should be considered in determining cut-off points for initiating treatment. Prospective research is useful to evaluate the effect of this change in the guideline on the rate of uncontrolled high blood pressure complications.

\section{Abbreviations \\ ACC/AHA: American College of Cardiology/American Heart Association; JNC7: Joint National Committee 7; YaHS: Yazd health study; \\ HTN: Hypertension; EMR: Eastern Mediterranean region; WHO: World Health Organization; BMl: Body mass index}

\section{Acknowledgments}

We acknowledge Yazd people for participation in the study who gave up their valuable time in the interviews and Yazd Central Health workers and managers for their help and support.

\section{Authors' contributions}

MM1 contributed to the design and conception of the study; analyzed and drafted the manuscript. MM2 contributed to the design of the study; supervised the researchers; contributed to the interpretation of the data and led on drafting and revising the manuscript.MM3 performed the statistical analysis and interpreted the results; and critically reviewed the manuscript.BB contributed to the design and conduction of the study and interpretation of the data and led on drafting the manuscript. All authors read and approved the final version of the manuscript and are accountable for their contributions.

\section{Funding}

This study was funded by Shahid Sadoughi University of Medical Sciences. Funding bodies had no role in data collection, analysis, and interpretation of data and in writing the manuscript.

\section{Availability of data and materials}

The data collected by Yazd Health Study are not open access but can be shared under conditions of collaboration and endowment. Data are available from the authors upon reasonable request and with permission of principal investigator. For further information, please visit YaHS website at www.yahsziba.com / www.yahs.ir.

\section{Ethics approval and consent to participate}

The research proposal was approved by the ethics committee of Shahid Sadoughi University of Medical Science, Yazd, Iran No:

IR.SSU.MEDICINE.REC.1396.311. The study was explained to all respondents willing to participate. All participants had the right to withdraw from the study at any time or refuse to respond any questions. A written informed consent was obtained from each participant before data collection. Participants with new diagnostics of hypertension were advised to refer their health center or physician for the follow-up. 


\section{Consent for publication}

Not applicable.

\section{Competing interests}

The authors declare that they have no competing interests.

\section{Author details}

${ }^{1}$ Yazd Cardiovascular Research Center, Shahid Sadoughi University of Medical Sciences, Yazd, Iran. ${ }^{2}$ Yale New Haven Medical Center, Waterbury Hospital, Waterbury, USA. ${ }^{3}$ Shahediah Cohort Study, Shahid Sadoughi University of Medical Sciences, Yazd, Iran.

\section{Received: 22 February 2020 Accepted: 5 August 2020}

Published online: 14 August 2020

\section{References}

1. Danaei G, Lu Y, Singh GM, Carnahan E, Stevens GA, Cowan MJ, et al. Cardiovascular disease, chronic kidney disease, and diabetes mortality burden of cardiometabolic risk factors from 1980 to 2010: a comparative risk assessment. Lancet Diab Endocrinol. 2014;2(8):634-47. https://doi.org/10. 1016/S2213-8587(14)70102-0.

2. Tran J, Mirzaei M. The population attributable fraction of stroke associated with high blood pressure in the Middle East and North Africa. J Neurol Sci. 2011;308(1-2):135-8. https://doi.org/10.1016/j.jns.2011.05.016.

3. Saeed KMI. Prevalence of hypertension and associated factors in Jalalabad City, Nangarhar Province, Afghanistan. Central Asian J Global Health. 2015; 4(1):134. https://doi.org/10.5195/cajgh.2015.134.

4. Afsargharehbagh R, Rezaie-Keikhaie K, Rafiemanesh H, Balouchi A, Bouya S, Dehghan B. Hypertension and pre-hypertension among Iranian adults population: a meta-analysis of prevalence, awareness, treatment, and control. Curr Hypertens Rep. 2019;21(4):27. https://doi.org/10.1007/s11906019-0933-z.

5. Mirzaei M, Moayedallaie S, Jabbari L, Mohammadi M. Prevalence of hypertension in Iran 1980-2012: a systematic review. J Tehran Univ Heart Center. 2016;11(4):159-67.

6. Gakidou E, Afshin A, Abajobir AA, Abate KH, Abbafati C, Abbas KM, et al. Global, regional, and national comparative risk assessment of 84 behavioural, environmental and occupational, and metabolic risks or clusters of risks, 1990-2016: a systematic analysis for the global burden of disease study 2016. Lancet. 2017;390(10100):1345-422. https://doi.org/10. 1016/S0140-6736(17)32366-8.

7. Bloch MJ. The worldwide prevalence of hypertension exceeds 1.3 billion. J Am Soc Hypertens. 2016;10(10):753-4. https://doi.org/10.1016/j.jash.2016.08. 006

8. Carey RM, Whelton PK. Prevention, detection, evaluation, and management of high blood pressure in adults: synopsis of the 2017 American College of Cardiology/American Heart Association hypertension guideline. Ann Intern Med. 2018;168(5):351-8. https://doi.org/10.7326/M17-3203.

9. CR WPK, Aronow WS, Casey DE Jr, Collins KJ, Dennison Himmelfarb C, SM DP, Gidding S, Jamerson KA, Jones DW, EJ ML, Muntner P, Ovbiagele B, Smith SC Jr, Spencer CC, Stafford RS, Taler SJ, Thomas RJ, Williams KA Sr, Williamson JD, Wright JT Jr. ACC/AHA/AAPA/ABC/ACPM/AGS/APhA/ASH/ ASPC/NMA/PCNA Guideline for the Prevention, Detection, Evaluation, and Management of High Blood Pressure in Adults: A Report of the American College of Cardiology/American Heart Association Task Force on Clinical Practice Guidelines. Hypertension. 2018;71(6):e13-e115. https://doi.org/10. 1161/HYP.0000000000000065.

10. Muntner P, Carey RM, Gidding S, Jones DW, Taler SJ, Wright JT Jr, et al. Potential US population impact of the 2017 ACC/AHA high blood pressure guideline. Circulation. 2018;137(2):109-18. https://doi.org/10.1161/ CIRCULATIONAHA.117.032582.

11. Khera R, Lu Y, Lu J, Saxena A, Nasir K, Jiang L, et al. The impact of 2017 ACC/AHA guidelines on the prevalence of hypertension and eligibility for anti-hypertensive therapy in the United States and China. BMJ. 2018;11:362: k2357. https://doi.org/10.1136/bmj.k2357.

12. Miller CS, Glick M, Rhodus NL. 2017 hypertension guidelines: new opportunities and challenges. J Am Dent Assoc. 2018;149(4):229-31. https:// doi.org/10.1016/j.adaj.2018.01.047.

13. Kibria GMA, Swasey K, Sharmeen A, Sakib MN, Burrowes V. Prevalence and associated factors of pre-hypertension and hypertension in Nepal: analysis of the Nepal demographic and health survey 2016. Health Sci Rep. 2018; 1(10):e83. https://doi.org/10.1002/hsr2.83.

14. Al Kibria GM, Swasey K, Choudhury A, Burrowes V, Stafford KA, Uddin SI, et al. The new 2017 ACC/AHA guideline for classification of hypertension: changes in the prevalence of hypertension among adults in Bangladesh. J Hum Hypertens. 2018;32(8):608.

15. Mirzaei M, Salehi-Abargouei A, Mirzaei M, Mohsenpour MA. Cohort Profile: The Yazd Health Study (YaHS): a population-based study of adults aged 2070 years (study design and baseline population data). Int J Epidemiol. 2017; 47(3):697-8h. https://doi.org/10.1093/ije/dyx231.

16. Mirzaei M, Mirzaei M, Bagheri B, et al. Awareness, treatment, and control of hypertension and related factors in adult Iranian population. BMC Public Health. 2020;20:667. https://doi.org/10.1186/s12889-020-08831-1.

17. Ogedegbe G, Pickering T. Principles and techniques of blood pressure measurement. Cardiol Clin. 2010;28(4):571-86. https://doi.org/10.1016/j.ccl. 2010.07.006

18. Chobanian AV, Bakris GL, Black HR, Cushman WC, Green LA, Izzo JL Jr, et al. The seventh report of the joint national committee on prevention, detection, evaluation, and treatment of high blood pressure: the JNC 7 report. JAMA. 2003;289(19):2560-71. https://doi.org/10.1001/jama.289.19. 2560.

19. Whelton PK, Carey RM, Aronow WS, Casey DE, Collins KJ, Himmelfarb CD, et al. 2017 ACC/AHA/AAPA/ABC/ACPM/AGS/APhA/ASH/ASPC/NMA/PCNA guideline for the prevention, detection, evaluation, and management of high blood pressure in adults: a report of the American College of Cardiology/American Heart Association task force on clinical practice guidelines. J Am Coll Cardiol. 2018;71(19):e127-248. https://doi.org/10.1016/ j.jacc.2017.11.006.

20. Who EC. Appropriate body-mass index for Asian populations and its implications for policy and intervention strategies. Lancet (London). 2004; 363(9403): 157

21. Esteghamati A, Etemad K, Koohpayehzadeh J, Abbasi M, Meysamie A, Khajeh E, et al. Awareness, treatment and control of pre-hypertension and hypertension among adults in Iran. Arch Iran Med. 2016;19(7):456-464. doi: 0161907/AIM.003.

22. Malekzadeh MM, Etemadi A, Kamangar F, Khademi H, Golozar A, Islami F, et al. Prevalence, awareness and risk factors of hypertension in a large cohort of Iranian adult population. J Hypertens. 2013;31(7):1364-71. https:// doi.org/10.1097/HJH.0b013e3283613053.

23. Asgari $S$, Khaloo $P$, Khalili D, Azizi F, Hadaegh F. Status of hypertension in Tehran: potential impact of the ACC/AHA 2017 and JNC7 guidelines, 20122015. Sci Rep. 2019;9(1):6382. https://doi.org/10.1038/s41598-019-42809-3.

24. Lee JH, Kim S-H, Kang S-H, Cho JH, Cho Y, Oh I-Y, et al. Blood pressure control and cardiovascular outcomes: real-world implications of the 2017 ACC/AHA hypertension guideline. Sci Rep. 2018;8(1):13155. https://doi.org/ 10.1038/s41598-018-31549-5.

25. Li D, Zeng $X$, Huang $Y$, Lei $H$, Li G, Zhang $N$, et al. Increased risk of hypertension in young adults in Southwest China: impact of the 2017 ACC/ AHA high blood pressure guideline. Curr Hypertens Rep. 2019;21(3):21. https://doi.org/10.1007/s11906-019-0926-y.

26. Gauer R, Larocque J. JNC 8: relaxing the standards. Am Fam Physician. 2014; 90(7):449-52.

27. Available from: https://www.acc.org/latest-in-cardiology/articles/2019/04/ 04/12/50/similarities-and-differences-between-the-2017-acc-aha-bpguideline-and-2017-ada-diabetes-and-htn-position-statement. Accessed July 26, 2019.

28. Group SR. A randomized trial of intensive versus standard blood-pressure control. N Engl J Med. 2015;373(22):2103-16. https://doi.org/10.1056/ NEJMoa1511939.

29. Group AS. Effects of intensive blood-pressure control in type 2 diabetes mellitus. N Engl J Med. 2010;362(17):1575-85. https://doi.org/10.1056/ NEJMoa1001286.

30. Williams B, Mancia G, Spiering W, Agabiti Rosei E, Azizi M, Burnier M, et al. 2018 ESC/ESH guidelines for the management of arterial hypertension. Eur Heart J. 2018;39(33):3021-104. https://doi.org/10.1093/eurheartj/ehy339.

31. Qaseem A, Wilt TJ, Rich R, Humphrey LL, Frost J, Forciea MA. Pharmacologic treatment of hypertension in adults aged 60 years or older to higher versus lower blood pressure targets: a clinical practice guideline from the American College of Physicians and the American Academy of family physicians. Ann Intern Med. 2017;166(6):430-7. https://doi.org/10.7326/M161785. 
32. Spruill TM, Gerber LM, Schwartz JE, Pickering TG, Ogedegbe G. Race differences in the physical and psychological impact of hypertension labeling. Am J Hypertens. 2012;25(4):458-63. https://doi.org/10.1038/ajh. 2011.258.

33. Leynen F, Backer GD, Pelfrene E, Clays E, Kittel F, Moreau M, et al. Increased absenteeism from work among aware and treated hypertensive and hypercholesterolaemic patients. Eur J Cardiovasc Prev Rehabil. 2006;13(2): 261-7. https://doi.org/10.1097/01.hjr.0000194420.62379.de.

34. Stewart JC, France CR, Sheffield D. Hypertension awareness and pain reports: data from the NHANES III. Ann Behav Med. 2003;26(1):8-14. https:// doi.org/10.1207/S15324796ABM2601_02.

35. Spruill TM, Feltheimer SD, Harlapur M, Schwartz JE, Ogedegbe G, Park Y, et al. Are there consequences of labeling patients with prehypertension? An experimental study of effects on blood pressure and quality of life. J

Psychosom Res. 2013;74(5):433-8. https://doi.org/10.1016/j.jpsychcores.2013. 01.009 .

36. Viera AJ, Lingley K, Esserman D. Effects of labeling patients as prehypertensive. J Am Board Fam Med. 2010;23(5):571-83. https://doi.org/ 10.3122/jabfm.2010.05.100047.

37. Egan BM, Zhao Y, Axon RN. US trends in prevalence, awareness, treatment, and control of hypertension, 1988-2008. JAMA. 2010;303(20):2043-50. https://doi.org/10.1001/jama.2010.650.

\section{Publisher's Note}

Springer Nature remains neutral with regard to jurisdictional claims in published maps and institutional affiliations.

Ready to submit your research? Choose BMC and benefit from:

- fast, convenient online submission

- thorough peer review by experienced researchers in your field

- rapid publication on acceptance

- support for research data, including large and complex data types

- gold Open Access which fosters wider collaboration and increased citations

- maximum visibility for your research: over $100 \mathrm{M}$ website views per year

At BMC, research is always in progress.

Learn more biomedcentral.com/submissions 